\title{
The Prevalence of Sonographically Thick Placenta and Its Effect on The Fetal and Maternal Outcome \\ Ahmed Hassan Eltagy ${ }^{1}$ MD, Ahmed Osama Abd Elmotaal ${ }^{1}$ MD and Ibrahim Galal Ibrahim Hassan Alhateem ${ }^{1, *} \mathrm{MB} \mathrm{BCh}$
}

\author{
* Corresponding Author: \\ Ibrahim Galal Alhateem \\ ebrahimalhateem@gmail.com
}

Received for publication January 31, 2020; Accepted March 16, 2020; Published online March 16, 2020.

Copyright 2020 The Authors published by Al-Azhar University, Faculty of Medicine, Cairo, Egypt. All rights reserved. This an openaccess article distributed under the legal terms, where it is permissible to download and share the work provided it is properly cited. The work cannot be changed in any way or used commercially.

doi: $10.21608 /$ aimj.2020.23054.1113

Obstetrics and Gynecology Department, Faculty of Medicine, Al-Azhar University Cairo, Egypt.

\begin{abstract}
Background: The placenta is responsible for the nutritive, respiratory and excretory functions of the fetus. It is often overlooked in the routine evaluation of the normal gestation, receiving attention only when an abnormality is detected.

Aim of the work: To determine the prevalence of sonographically thick placenta and the relation of thick placenta to fetal \& maternal outcome.

Patients and methods: prospective study included 25 pregnant women with thick placenta, attending to El-Hussein Obstetric outpatient clinics, as group A. 25 pregnant women with normal placental thickness were included as group B. US examination was recorded at 2 nd and 3 rd trimesters. After delivery, the placenta was weighted in grams.

Results: There was statistically significant higher incidence of HTN, IUGR and NICU admission in group A rather than group B. There was statistically significant lower GA, birth weight andApgar score in group A compared to group B. There was statistically significant higher placental weight in group A compared to group B. There was statistically significant increase in placental thickness in patients with maternal HTN, DM and thyroid disease.

Conclusion: Increased placental thickness is not diagnostic of any specific disorder but may contribute to the management of a fetus at risk. Measurement of Placental Thickness is a good predictor tool for estimating the fetal weight. Thick placenta is associated with higher incidence of low GA and low birth weight. A thick placenta should be regarded as a risk factor and needs good follow up.
\end{abstract}

Keywords: Sonography; Thick placenta; Fetus; Maternal outcome.

Disclosure: The authors have no financial interest to declare in relation to the content of this article. The Article Processing Charge was paid for by the authors.

Authorship: All authors have a substantial contribution to the article.

\section{INTRODUCTION}

The human placenta develops with the principal function of providing nutrients and oxygen to the fetus ${ }^{1}$.

Adequate fetal growth and subsequent normal birth weight depends on the efficient delivery of nutrients from the mother to the fetus via normally functioning utero-placental organ ${ }^{2}$.

Normal development of placenta during gestation is necessary for supporting of a healthy fetus ${ }^{3}$.

In the first trimester, placental growth is more rapid than that of the fetus. But by approximately 17 postmenstrual weeks, placental and fetal weights are approximately equal. By term, placental weight is approximately one sixth of fetal weight. According to Boyd and Hamilton (1970), the average placenta at term is $185 \mathrm{~mm}$ in diameter and $23 \mathrm{~mm}$ in thickness, with a volume of $497 \mathrm{ml}$ and a weight of
$508 \mathrm{~g}$. These measurements vary widely, and there are multiple variant placental forms and several types of umbilical cord insertions ${ }^{4}$.

Normal placental function and structure is a necessary factor for the formation of a healthy fetus and consequently normal birth weight ${ }^{5}$.

On the other hand, any impairment in its development may have a profound impact on fetal development and pregnancy outcome ${ }^{\mathbf{1}}$.

The ratio of the birth weight to the placental weight has been used since the 1940s as an index for the appropriateness of fetal growth ${ }^{6}$.

The definitive placenta is clearly visible on ultrasound from approximately 9-10 weeks of gestation, when it demonstrates a uniformly granular echogenic pattern ${ }^{7}$. 
Ultrasonography (US) enables the evaluation of the placenta and the detection of placental abnormalities using different parameters such as placental thickness and volume or especial techniques like three-dimensional (3D) power Doppler ${ }^{8}$.

Ultrasound measurement of placental thickness is a relative simple, reproducible and clinical useful way, which had been used for more than two decades ${ }^{8}$.

Several parameters were used to assess fetal growth in order to quantify intrauterine environmental adequacy and fetal well-being'.

Early detection of any pathology in the placental bed and villi helps obstetrician to consider prenatal care precisely ${ }^{10}$.

The rate of placental growth appears to be an important determinant of birth weight, with the rate between 17 and 20 weeks gestation being a predictor of fetal abdominal and head circumference, femoral length and biparietal diameter; weaker associations are observed for placental growth earlier in pregnancy ${ }^{\mathbf{1 1}}$.

Several aspects of placental growth including volume, weight, and plate area were investigated in different researches in order to find their correlation with fetal anthropometry ${ }^{2}$.

Abnormally thick placentas have been correlated with adverse pregnancy outcome ${ }^{\mathbf{1 2}}$.

Patients with ITP or preeclampsia had thicker placenta in comparison with normal pregnant women ${ }^{13}$.

Increased placental thickness is not diagnostic of any specific disorder but may contribute to the management of a fetus at risk ${ }^{14}$.

Also, more frequent thick placentas in cases with absent end-diastolic umbilical arterial flow were found. It seems that intervillous perfused more slowly when the villous tree is too complex or too dense ${ }^{15}$.

Definition of placentomegaly was different in various reports on the basis of gestational age, measurement technique and feto-maternal condition during pregnancy.

A placental thickness more than $40 \mathrm{~mm}$ at term is associated with gestational diabetes, intrauterine infections and hydrops fetalis ${ }^{\mathbf{1 6}}$.

The aim of this work is to determine prevalence of sonographically thick placenta, relation of thick placenta to fetal and maternal complications during pregnancy and the outcome of these pregnancies.

\section{PATIENTS AND METHODS}

Study design: prospective study of 50 pregnant female's age (18-45 years) presenting for routine antenatal care for 28 weeks (from the 13th week of pregnancy).

Study place: Al-Hussein University.
Study time: From June 2018 to January 2019.

Inclusion criteria: The study included patients with ages 18-45 years old, only single viable pregnancy, gestational age: from the 13th week of pregnancy and normal fetal heart rate.

Exclusion criteria: Women with multiple pregnancies, intra uterine fetal death, maternal major systemic disease before pregnancy as DM and hypertension, major fetal congenital malformation such as anencephaly and hydrocephaly, premature rupture of membranes and placenta previa, accreta, increta and percreta were excluded from the study.

All the patients will be submitted to the following steps: Informed consent will be taken from each patient, full history, blood pressure measurement, bloody mass index measurement, general examination and abdominal examination.

Obstetric ultrasound for checking the number of fetuses, viability,gestational age, placental location and thickness and congenital fetal malformations.

Investigations: CBC, R.B.S, Urine analysis, liver and kidney functions, and Gestational age was determinded by reliable recalling of the last menstrual period and confirmed by an U.S examination in the first trimester (CRL). The study was approved by institutional ethics committee of the hospital. Placental thickness was measured by placing the ultrasound transducer perpendicularly to the plane of the placenta, in the area of the cord insertion, near the mid-placental portion 17.

Sonography was performed using a $3.5 \mathrm{MHz}$ convex transducer. If patients underwent multiple exams during their pregnancies, the first sets of measurements were used in this study. Placenta was diagnosed thick when measured more than $4 \mathrm{~cm}$ perpendicular to chorionic plate at the insertion of the umbilical cord during third trimester 12 .

The present study includes 50 cases divided into two groups:

Group A (the study group): With thick placenta (Placenta were diagnosed thick when measured at least $4 \mathrm{~cm}$ perpendicular to chorionic plate at the insertion of umbilical).

Group B (the control group): With normal placenta (less than $4 \mathrm{~cm}$ ).

At the time of delivery, the birth weight, fetal sex and mode of delivery were taken. After delivery, the placenta was weighted in grams.

Fetal and neonatal status and morbidity including baby APGAR scores, fetal distress or fetal death and admission to ICU were also determined. 
Follow up during the study for:

The mother: special attention is given for preeclampsia, placental abruption, placenta previa, gestational DM and placental insufficiency.

For the baby: Hydrops fetalis, fetal malformation and small gestational age.

Statistical analysis: Statistical presentation and analysis of the present study was conducted, using the mean, standard deviation, student t- test, Chisquare, Linear Correlation Coefficient by SPSS VI7.

- Unpaired Student T-test was used to compare between two groups in quantitative data.

- Chi-square the hypothesis that the row and column variables are independent, without indicating strength or direction of the relationship. Pearson chi-square and likelihood-ratio chi-square. Fisher's exact test and Yates' corrected chi- square are computed for $2 \times 2$ tables.

- Linear Correlation Coefficient [r]: was used for detection of correlation between two quantitative variables in one group.

- ROC-curve: -Receiver Operating Characteristic curve analysis

$\checkmark$ Sensitivity: - Probability that the test results will be positive when the disease is present (true positive rate, expressed as a percentage).

$\checkmark$ Specificity: - Probability that the test results will be negative when the disease is absent (true negative rate, expressed as a percentage).

$\checkmark$ Accuracy: - the ratio of the true positive and true negative on all patients.

\section{Statistical Methods:}

Sample size justification:

MedCalc ${ }^{\circledR}$ version 12.3.0.0 program "Ostend, Belgium" was used for calculations of sample size, statistical calculator based on $95 \%$ confidence interval and power of the study $80 \%$ with $\alpha$ error $5 \%$, According to a previous study by Afrakhteh et al., 201318, showed that the mean of placental thickness $41.5 \pm 11.2$ in GA <36 weeks, while mean of placental thickness $35.9 \pm 5.7$ in GA $36-42$ weeks, with p-value 0.003 , also placental thickness of birth weight $\leq 2.500 \mathrm{~g}$ mean was $37.4 \pm 10.8$, birth weight $2.500-4.000 \mathrm{~g}$ mean placental thickness was $35.9 \pm 5.5$, and $>4000 \mathrm{~g}$ of birth weight was mean of placental thickness $41.6 \pm 5.1$, with p-value 0.1 , So it can be relied upon in this study, based on this assumption, sample size was calculated according to these values produced a minimal samples size of 48 cases were enough to find such a difference. Assuming a drop-out ratio of 5\%, the sample size will be 50 cases, subdivided into two groups, Group A: $n=25$ and Group A: $n=25$

\section{RESULTS}

\begin{tabular}{|c|c|c|c|c|}
\hline Variable & $\begin{array}{c}\text { Study group } \\
(\mathrm{n}=25)\end{array}$ & $\begin{array}{c}\text { Control group } \\
(n=25)\end{array}$ & Chi-square test & p-value \\
\hline $\begin{array}{l}\text { Maternal age } \\
<20 \text { years } \\
20-29 \text { years } \\
30-39 \text { years } \\
>40 \text { years } \\
\text { Mean+SD }\end{array}$ & $\begin{array}{c}3(12 \%) \\
15(60 \%) \\
6(24 \%) \\
1(4 \%) \\
27.96 \pm 5.31\end{array}$ & $\begin{array}{c}5(20 \%) \\
15(60 \% \\
5(20 \%) \\
0(0 \%) \\
26.20 \pm 4.98\end{array}$ & 1.591 & 0.662 \\
\hline $\begin{array}{l}\text { Parity } \\
\text { Primi } \\
\text { Multi }\end{array}$ & $\begin{array}{c}8(32 \%) \\
17(68 \%)\end{array}$ & $\begin{array}{l}7(28 \%) \\
18(72 \%\end{array}$ & 0.008 & 0.928 \\
\hline $\begin{array}{l}\text { Maternal BMI } \\
\text { Under weight } \\
\text { Normal weight } \\
\text { Over weight } \\
\text { Obese }\end{array}$ & $\begin{array}{l}0(0 \%) \\
6(24 \%) \\
9(36 \%) \\
10(40 \% \\
\end{array}$ & $\begin{array}{c}0(0 \%) \\
3(12 \% \\
13(52 \% \\
14(56 \% \\
\end{array}$ & 1.956 & 0.376 \\
\hline $\begin{array}{l}\text { Fetal sex } \\
\text { Male } \\
\text { Female }\end{array}$ & $\begin{array}{l}11(44 \%) \\
14(56 \%)\end{array}$ & $\begin{array}{l}12(48 \%) \\
13(52 \%)\end{array}$ & 1.786 & 0.182 \\
\hline
\end{tabular}

Using: Chi-square test; $\mathrm{p}$-value $>0.05 \mathrm{NS}$

Table 1: Comparison between study group and control group according to baseline characteristics. 


\begin{tabular}{|c|c|c|c|c|}
\hline \multirow[t]{2}{*}{ Variable } & $\begin{array}{c}\text { Study group } \\
(\mathrm{n}=25)\end{array}$ & \multirow[t]{2}{*}{$\mathbf{P}$} & $\begin{array}{c}\text { Control group } \\
(n=25)\end{array}$ & \multirow[t]{2}{*}{$\mathbf{P}$} \\
\hline & Mean \pm SD & & Mean \pm SD & \\
\hline $\begin{array}{l}\text { Maternal age } \\
<20 \text { years } \\
20-29 \text { years } \\
30-39 \text { years } \\
>40 \text { years }\end{array}$ & $\begin{array}{l}5.21 \pm 0.13 \\
4.75 \pm 0.24 \\
4.32 \pm 0.31 \\
5.13 \pm 0.00\end{array}$ & $0.017 *$ & $\begin{array}{l}2.08 \pm 30 \\
1.97 \pm .40 \\
2.00 \pm .10 \\
1.99 \pm .34\end{array}$ & 0.362 \\
\hline $\begin{array}{l}\text { Parity } \\
\text { Primi } \\
\text { Multi } \\
\end{array}$ & $\begin{array}{l}5.16 \pm 0.14 \\
4.43 \pm 0.28 \\
\end{array}$ & 0.149 & $\begin{array}{l}1.92 \pm .34 \\
2.02 \pm .35 \\
\end{array}$ & 0.072 \\
\hline $\begin{array}{l}\text { Maternal BMI } \\
\text { Normal weigtht } \\
\text { Over weigtht } \\
\text { Obeise }\end{array}$ & $\begin{array}{l}4.67 \pm 0.33 \\
4.94 \pm 0.21 \\
4.59 \pm 0.27\end{array}$ & 0.362 & $\begin{array}{l}2.05 \pm .36 \\
2.06 \pm .27 \\
1.88 \pm .41\end{array}$ & 0.063 \\
\hline
\end{tabular}

Using: One Analysis of Variance;

P-value $>0.05 \mathrm{NS}$; *p-value $<0.05 \mathrm{~S}$; **p-value $<0.001 \mathrm{HS}$

Table 2: Relation between placental thickness and baseline characteristics.

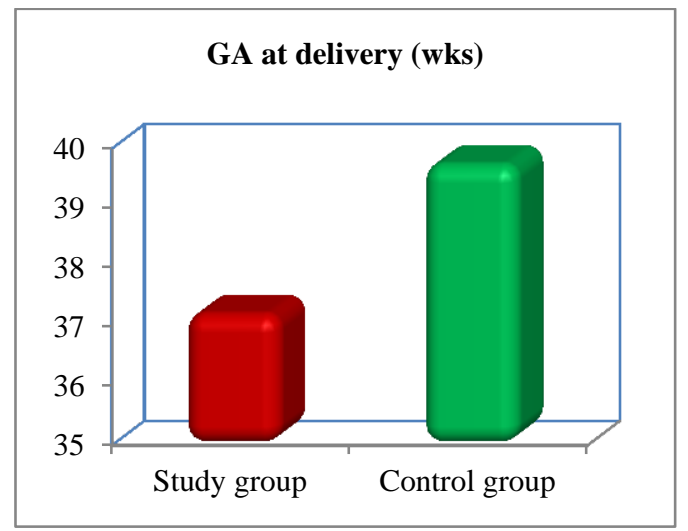

Fig. 1: Bar chart between two groups according to GA at delivery.

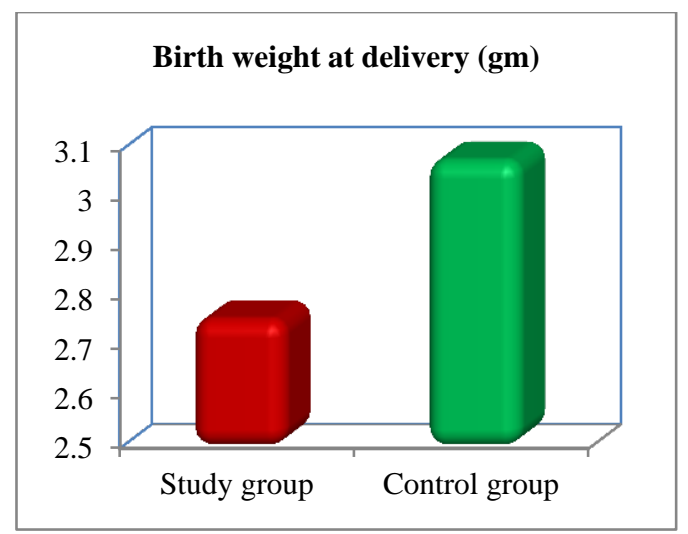

Fig. 2: Bar chart between two groups according to birth weight at delivery. 


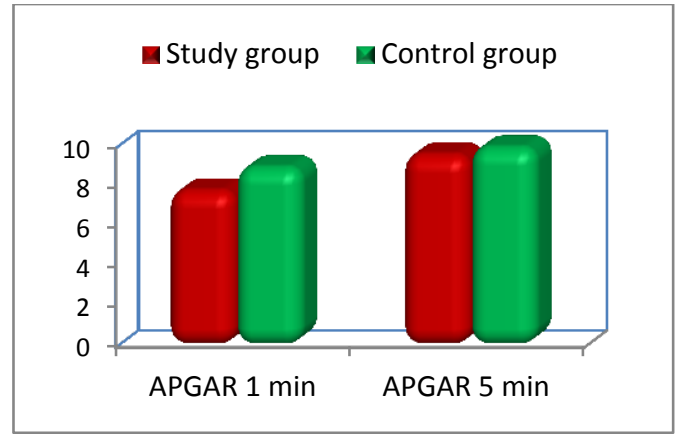

Fig. 3: Bar chart between two groups according to Apgar score.

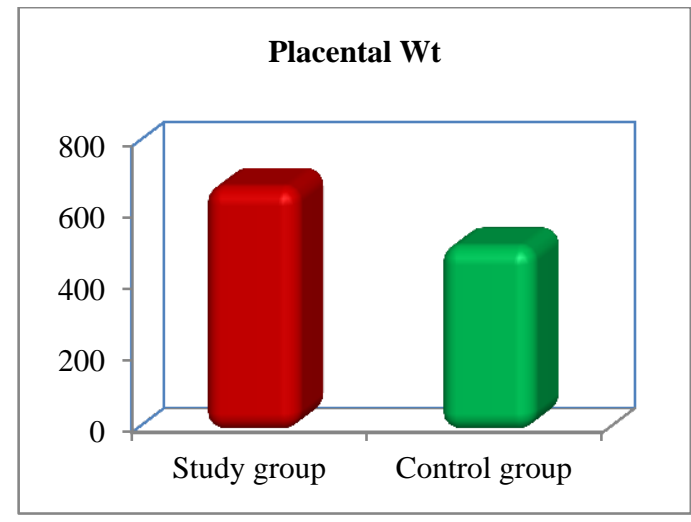

Fig. 4: Bar chart between two groups according to placental weight.

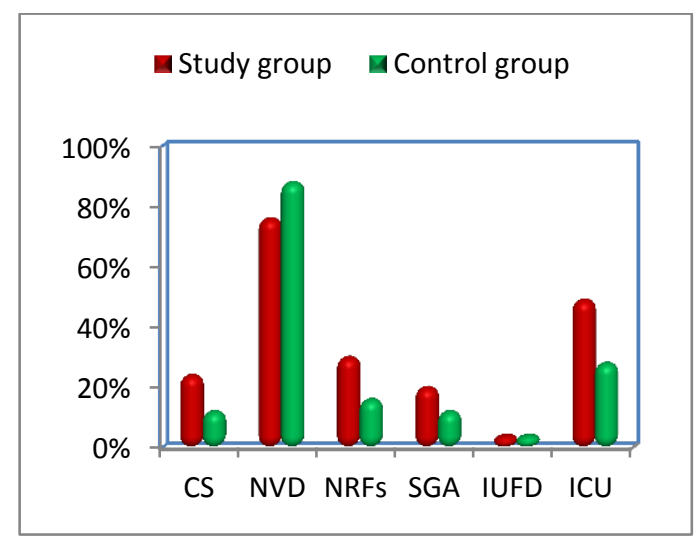

Fig. 5: Incidence of Perinatal Morbidity.

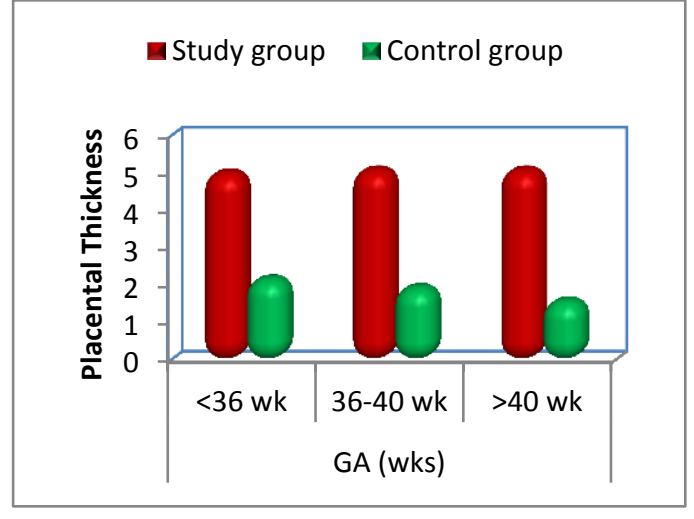

Fig. 6: Comparison between group A and group B regarding Duration of Pregnancy.

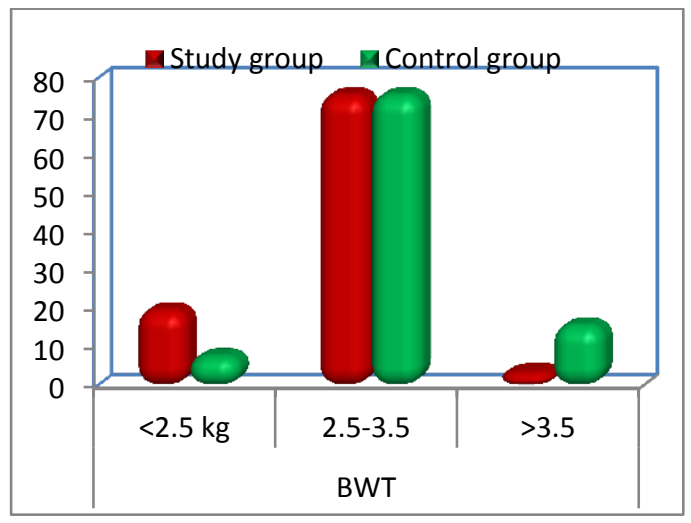

Fig.7: Comparison between study group and control group according to BWT. 


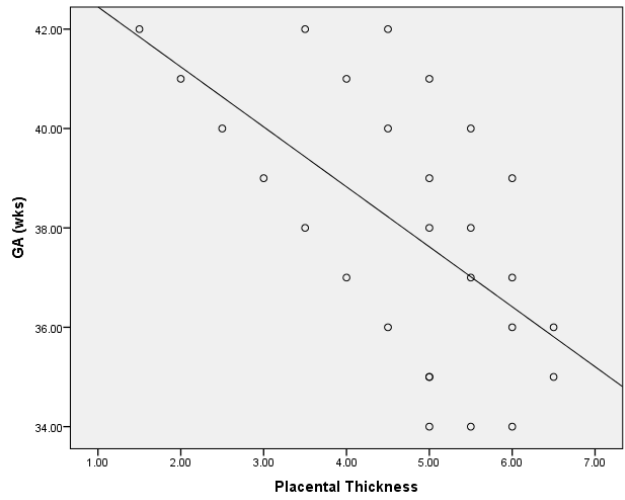

Fig. 8: Correlation between GA and placental thickness.

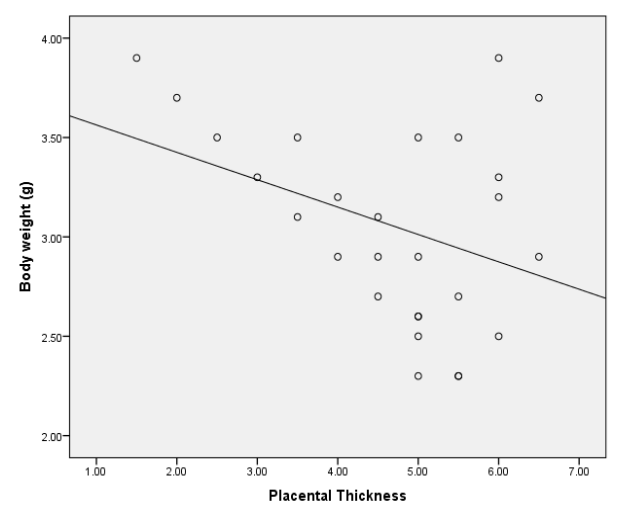

Fig. 9: Correlation between birth weight and placental thickness.

\section{DISCUSSION}

Normal placental functions and structure is a necessary factor for the formation of a healthy fetus and consequently normal birth weight ${ }^{5}$.

Many pathological conditions could induce placentomegaly a result of inflammation, edema, or compensatory hypertrophy, increased placental thickness is not diagnostic of any specific disorder but may contribute to the management of a fetus at risk ${ }^{14}$.

Early detection of any pathology in the placental bed and villi helps obstetrician to consider prenatal care precisely ${ }^{19}$.

Ultra-structural study of Macara et al., $(1996)^{20}$ of placenta indicates that thickening of the basal lamina and increased deposition of collagen and laminin together with congestion of the capillaries by erythrocytes is the cause of limited oxygen transfer from the intervillous space to the growth retarded fetus.

In a recent study, investigators proposed that sonographic increase of placental thickness during second trimester is due to over-inflation of the intervillous space by maternal blood rather than by adaptive formation of functional placental tissue ${ }^{21}$.
Recently, investigators are trying to increase detection rate of early sign for impaired placentation by combination of ultrasound findings with placental hormones such as human chorionic gonadotropin (hCG),progesterone and pregnancy associated plasma protein A (PAPP-A) ${ }^{1}$.

Several aspects of placental growth including volume, weight, and plate area were investigated in different researches in order to find their correlation with fetal anthropometry ${ }^{2}$.

Sonographic measurements of placental thickness are reported to be a relative simple and clinical useful way to detect "early warning signs" which could be done in any unequipped obstetrician center ${ }^{22}$.

Therefore, the aim of this work was to determine relation of thick placenta to fetal \& maternal complication during pregnancy and the outcome of these pregnancies.

This prospective study included Twenty-five pregnant women with thick placenta, attending the Department of Obstetrics and Gynecology, Al-Azhar University Hospitals. Twenty-five pregnant women with normal placental thickness were included as control group.

There was no statistically significant maternal weight in study group compared to control group.

Unlike our results, Bapiste-roberts, et al., $2008^{23}$ found that placental thickness increases with increase of maternal body mass index. This study was applied on Malay, Chinese and Indian ethnic groups.

There was no statistically significant maternal age and parity in study group compared to control group.

Similar to our results, Elchalai, et al., $2000^{14}$ found no correlation was found between placental thickness and maternal age or parity.

Results of the current study showed statistically significant lower GA, in study group compared to control group.

Similar to our results, Miwa et al, $2014^{24}$ found that gestational age at delivery was earlier in the cases with thick placenta than in those without thick placenta.

Study by Mital et al., $2002^{25}$ reported the use of placental thickness as an indicator of gestational age.

Results of the current study showed statistically significant lower birth weight in study group compared to control group.

Similar to our results, Miwa et al., $2014^{24}$ found that birth weight was smaller in the cases with thick placenta than in those without thick placenta.

Results of the current study showed statistically significant lower APGAR (l) $\mathrm{min}$ and (5) $\mathrm{min}$ in study group compared to control group.

Similar to our results, Miwa et al., $2014^{24}$ found that the values of Apgar score at 1 minute in the cases with thick placenta were significantly lower than in those without thick placenta. 
Results of the current study show, statistically significant higher occurrence of SGA in study group compared to control group.

Suriet et al., $2013^{1}$ Showed that Investigator are trying to increase detection rate of early sign for impaired placentation by ultrasound findings. In the study of Macaraet al., $1996^{20}$ of placenta indicates that thickening of the basal lamina and increased deposition of collagen and laminin together with congestion of the capillaries by erythrocytes is the cause of limited oxygen transfer from the intervillous space to the growth retarded fetus.

In a recent study, Porat et al., 2012 21 investigators proposed that sonographic increasement of placental thickness during second trimester is due to overinflation of the intervillous space by maternal blood rather than by adaptive formation of functional placental tissue.

Results of the current study showed statistically significant higher incidence of emergency cesarean section, ICU admission, non- reassuring fetal status, Intra Uterine Fetal Death, in study group compared to control group.

Similar to our results, Miwa et al., $2014^{24}$ found that perinatal morbidity and neonatal conditions were worse in cases associated with thick placentas. They found that the rates of emergency cesarean section deliveries, ICU admission, non-reassuring fetal status, Intra Uterine Fetal Death in study group compared to control also congenital anomalies were significantly higher in cases with thick placenta than without thick placenta.

Tsang- Ming Koi et al., $2005^{26}$, found that the incidence of the perinatal mortality and the fetal anomalies were greater in the subjects with thick placentae.

Unlike our results, Thompson et al., $2002^{6}$ found no correlation between a thick placenta and poor obstetrical outcome.

Results of the current study showed, statistically significant higher occurrence of GDM in study group compared to control group.

Similar to our results, Benrishke $\mathrm{K}$ et al., $2012^{27}$ found that a placental thickness of $>40 \mathrm{~mm}$ at term is associated with gestational diabetes.

This can be explained by the fact that, glucose, which forms the main energy substrate for the fetus is delivered by the mother through stores in the liver, muscle and adipose tissue, modulated by insulin. Alterations in the availability and passage of these substances are responsibility for gestational diabetes mellitus.

Unlike our results, Miwa et al., 2014 ${ }^{24}$ found no significant difference was observed in GDM rates in cases with thick placenta.

Results of the current study showed statistically significant higher occurrence of PIH in study group compared to control group.

Similar to our results, Afrakhteh $\mathrm{M}$ et al., $2013^{18}$ found that patients with preeclampsia had thicker placenta in comparison with normal pregnant women.

This observation was similar to the reports of previous studies as Dombrowski, et al., 1992

Raioet al., $2004^{12}$ stated that abnormally thick placentas have been correlated with adverse pregnancy outcome. Also, more frequent thick placenta in cases with absent end-diastolic umbilical arterial flow was found. It seems that intervillous perfused more slowly when the villous tree is too complex or too dense.

Results of the current study show statistically significant higher incidence of Abruptio placenta in study group compared to control group.

Similar to our results, Miwa et al., $2014^{24}$ found that perinatal morbidity and neonatal conditions were worse in cases associated with thick placentas asabruptio placentae, PIH, and congenital anomalies were significantly higher in cases with thick placenta than without thick placenta.

Tsang- Ming Koi etal., $2012^{26}$ found that the incidence of the perinatal mortality and the fetal anomalies were greater in the subjects with thick placentas.

There was statistically significant correlation between GA and Birth Weight and placental thickness.

Similar to our results, Afrakhteh et al., $20133^{18}$ found a significant correlation between placental thickness and birth weight in the second and third trimesters. $(\mathrm{r}=0.15, \mathrm{p}=0.03 ; \mathrm{r}=0.14, \mathrm{p}=0.04$ correspondingly $)$

Correlation of placental thickness with gestational age and fetal growth was also reported in a research by Karthikeyan et al., $2012^{28}$ andOhagwuet al., $2009^{29}$ found a significant correlation between placental thicknesses and estimated fetal weight in the second and third trimesters. $(r=0.61$ and $r=0.57$ respectively)

Habib et al., $2002^{5}$ in their study, said that the placental thickness was $22 \mathrm{~mm}$ at 36 weeks in the fetuses which weighed $<2500 \mathrm{gm}$ and that the Placental thickness was $34.8 \mathrm{~mm}$ at 36 weeks in the fetuses which weighed $>2500 \mathrm{gm}$. They concluded that Placental thickness was a predictor of Low Birth Weight infants.

Also, unlike our results, Sanin et al., $2001{ }^{30}$ found that the placenta however was shown to have a nonlinear relation to birth weight.

Kinare et al., $2000^{31}$ found that placental size in midpregnancy independently has relationship with birth parameters although most of the placental growth occurred in the third trimester.

Other researchers like Goldenberg et al., $1997^{32}$ stated that birth size was only predicted in the third trimester by fetal ultrasound measurements.

However, many studies as Elchalal et al., $2000^{14}$ and Kinare et al., $2000{ }^{31}$ which were retrospective or cross-sectional in design and could not truly show the relationship between placental measurements and 
fetal outcome. It seems reasonable that serial evaluation of placental thickness in second and third trimester could help to determine normal development and functional placenta and deserve as a good predictor of fetal growth and birth weight.

\section{CONCLUSION}

Increased placental thickness is not diagnostic of any specific disorder but may contribute to the management of a fetus at risk. Measurement of Placental Thickness by U/S is a good predictor tool for estimating the fetal weight. Thick placenta is associated with higher incidence of low gestational age and low birth weight. Ultrasound forms a readily available, fairly safe, and forms an effective noninvasive teqnique. A thick placenta should be regarded as a risk factor and needs good follow up during the rest of pregnancy.

\section{REFERENCES}

1. Suri S, Muttukrishna $S$ and Jauniaux E. 2Dultrasound and endocrinologic evaluation of placentation in early pregnancy and its relationship to fetal birth weight in normal pregnancies and preeclampsia: placenta. 2013 Sep; 34(9): 745-50.

2. Azpurua H, Funai EF and Coraluzzi LM Determination of placental weight using twodimensional sonography and volumetric mathematic modeling. Am J Perinatol.2010;27(2):151-60

3. Salafia CM, Zhang J and Miller RK. Placental growth patterns affect birth weight for given placental weight.Birth Defects: Res A Clin Mol Teratol.2007; 79(4):281-8.

4. Cunningham FG, Leveno $\mathrm{KJ}$ and Bloom SL Williams's obstetrics, 23rd edition. United States of America: McGraw-Hill Companies.2010; Chapter 3 Maternal and Fetal Anatomy and Physiology, p.54.

5. Habib FA. Prediction of Low Birth Weight Infants from Ultrasound Measurement of Placental Diameter and Placental Thickness: Ann Saudi Med.2002; 22(5-6): 312-4.

6. Thompson MO, Vines SK, Aquilina J, et al. Are placental lakes of any clinical significance?: Placenta. 2002 sep-oct;23(8,9):68590.

7. Jauniaux E, Watson A and Ozturk O. In-vivo measurement of intrauterine gases and acid-base values early in human pregnancy: Hum Reprod.1999;14(11):2901-4.

8. Chen M, Leung KY and Lee CP. Placental volume measured by three-dimensional ultrasound in the prediction of fetal alpha(0)-thalassemia: a preliminary report. Ultrasound ObstetGynecol.2006; 28:166-72.
9. Hafner E, Philipp T and Schuchter K. Secondtrimester measurements of placental volume by three-dimensional ultrasound to predict small-forgestational-age infants: Ultrasound ObstetGynecol.1998; 12(2):97-102.

10. Tongsong T and Boonanurak P. Placental thickness in the first half of pregnancy: $J$ Clin Ultrasound.2004; 32:231.

11. Holroyd CR, Harvey NC and Crozier SR. Placental size at 19 weeks predicts offspring bone mass at birth: findings from the Southampton Women's Survey. Placenta.2012; 33(8): 623-629.

12. Raio L, Ghezzi F and Di Naro E. Perinatal outcomes of fetuses with a birth weight greater than 4500g: an analysis of 3365 cases. Eur J Obstet Gynecol Reprod Biol. 2003Aug 15;109(2):160-5.

13. Dombrowski MP, Wolfe HM, Saleh A, et al. The sonographically thick placenta: a predictor of increased perinatal morbidity and mortality. Ultrasound Obstet Gynecol.1992; 2:25255 .

14. Elchalal U, Ezra Y and Levi Y. Sonographically thick placenta: a marker for increased perinatal risk-a prospective cross-sectional study. Placenta.2000; 21:268-72.

15. Nordenvall, M., Ullberg, U., Laurin, J.,et al. Placental morphology in relation to umbilical artery blood velocity waveforms: E.J of Obstet \& Gyneco. and Reproductive Biology.1991; 40(3), 179-90.

16. Benirschke K, Burton GJ and Baergen R .Pathology of the Human Placenta:2012; 6:908. https://www.springer.com/gp/book/97836422394 $\underline{03}$

17. Wang, S., Chen, J., Beall, M., et al. Expression of aquaporin 9 in human chorioamniotic membranes and placenta: Am. J. obstet. gynecol.2004; 191(6), 2160-67.

18. Afrakhteh, M., Moeini, A., Taheri, et al.Correlation between placental thickness in the second and third trimester and fetal weight: Revista Brasileira de Ginecologia e Obstetrícia.2013; 35(7), 317-22.

19. Tongsong $\mathrm{T}$ and Boonanurak P. Placental thickness in the first half of pregnancy: $J$ Clin Ultrasound.2004; 32:231.

20. Macara L, Kingdom JC and Kaufmann P .Structural analysis of placental terminal villi from growthrestricted pregnancies with abnormal umbilical artery Doppler waveforms: Placenta.1996; 17(1):37-48 
21. Porat S, Fitzgerald B and Wright E. Placental hyperinflation and the risk of adverse perinatal outcome: Ultrasound Obstet Gynecol. 2013 Sep; 42(3):315-21.

22. Harris RD, Cho C and Wells WA. Sonography of the placenta with emphasis on pathological correlation. Semin Ultrasound CT MR.1996; 17(1):66-89.

23. Baptiste-Roberts K, Salafia M and Nicholson K, et al. Maternal risk factors for abnormal placental growth: the national collaborative perinatal project. BMC pregnancy and childbirth.2008; 8(1), 44.

24. Miwa M, Mayumi T, Hiromi S, et al. A thick placenta: a predictor of adverse pregnancy outcomes.springer plus.2014;3:353. DOI: 10.1186/2193-1801-3-353

25. Mital P, Hooja N and Mehndiratta K. Placental thickness: a sonographic parameter for estimating gestational age of the fetus. Indian $J$ Radiol Imaging.2002; 12:553.

26. Tsang-Ming Koi, M. D. Tseng, L. H. Hsu, et al. scanning of placental thickness and the prenatal diagnosis of homozygous alpha thalassaemia-1 in the 2nd trimester: Japanese J. on Obstet. and Gynecol. 2005; 17(4), 112-33.
27. Benirschke K, and Kaufmann P. Anatomy and pathology of the umbilical cord and major fetal vessels: In Pathology of the human placenta. Springer, NY. 2000; p. 335-98.

28. Karthikeyan T, Subramaniam RK and Johnson W. Placental thickness \& its correlation to gestational age \&foetal growth parameters: a cross sectional ultrasonographic study. J Clin Diagn Res.2012; 6(10):1732-5.

29. Abu PO, Ohagwu CC and Eze JC. Correlation between Placental Thickness and Estimated Fetal Weight in Nigerian Women: Ibnosina J. of Med. and Biomed. Sciences. 2009; 1(3):80-5.

30. Sanin H, Lopez R, Olivares $T$, et al. .Relation between birth weight and placenta weight: Neonatology.2001; 80(2), 113-7.

31. Kinare S, Natekar S, Chinchwadkar C, et al. Low midpregnancy placental volume in rural Indian women: A cause for low birth weight? . Am. J. Obstet. and gynecol. 2000; 182(2), 443-8.

32. Goldenberg RL, Cliver SP, Neggers Y, Copper RL, DuBard MD, Davis RO. The relationship between maternal characteristics and fetal and neonatal anthropometric measurements in women delivering at term: a summary. Acta ObstetGynecol Scand.1997; 165:8-13. 